\title{
Princípios Norteadores da Prática Psicológica na Atencão Básica: Em Busca da Integralidade
}

Guiding Principles to the Psychological Practice in the Basic Attention: Pursuing Integrality

Principios Norteadores de la Práctica Psicológica en la Atención Básica: En Busca de la Integralidad

Francisca Marina de Souza Freire \& Ana Alayde Werba Saldanha Pichelli

Universidade Federal da Paraíba

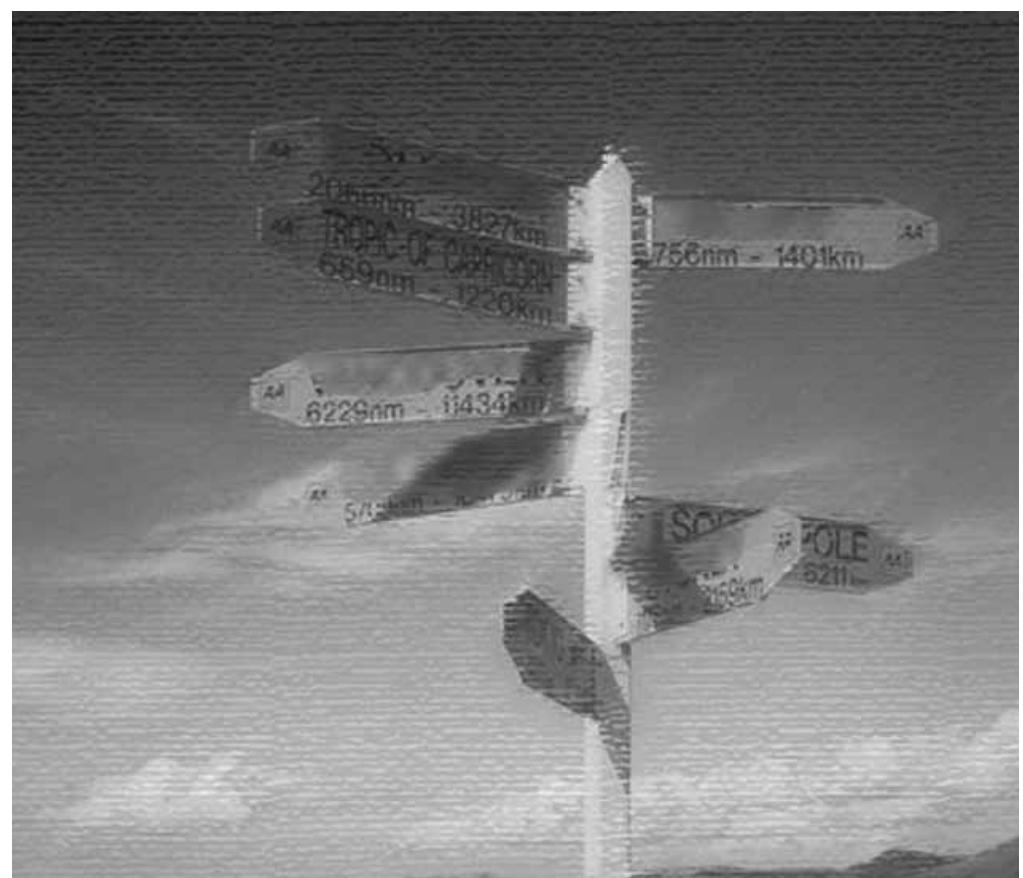


Resumo: A interdisciplinaridade é uma das principais estratégias empregadas pelo Sistema Único de Saúde (SUS) para o oferecimento de serviços no setor público, especialmente os que envolvem os cuidados primários; nesse quadro, encontra-se a Psicologia. Este estudo busca verificar quais princípios servem de norte à prática dos psicólogos de João Pessoa, PB nos serviços de Atenção Básica à Saúde. Participaram 17 psicólogos, a maioria do sexo feminino, com idade que variava entre 23 e 58 anos $(M=44 ; D P=11,8)$. Dos princípios norteadores à prática desses profissionais, levantados por meio de um questionário sociolaboral, emergiram três categorias temáticas: 1) os princípios e diretrizes do SUS, 2) os valores pessoais e 3) a concepção de saúde. Ademais, como condições influenciadoras, obtiveram destaque as questões referentes às experiências pessoais e profissionais anteriores. Diante disso, pôde-se verificar uma deficiência no conhecimento dos psicólogos diante das políticas públicas, em especial, no que tange ao SUS, o que demanda não só urgentes transformações em sua formação acadêmica mas também em seu envolvimento político frente às questões sociais e aos usuários.

Palavras-chave: Atuação do psicólogo. Integralidade. Atenção primária de saúde. Políticas públicas.

\begin{abstract}
Interdisciplinarity is one of the main strategies used by the Sistema Único de Saúde (SUS) to provide assistance to the public sector, especially to those that involve primary care. Psychology is related to this context. This study aims to verify which principles serve as guides to the psychologists' practice in João Pessoa/PB in the services of Health Basic Attention. A number of 17 psychologists, most of them women, with ages that ranged from 23 to 58 years old $(M=44 ; S D=11,8)$ participated in this research. From the guiding principles of these professionals' practice, raised by a socio-labor questionnaire, three thematic categories emerged: 1) the principles and guidelines of the SUS, 2) the personal values and 3) the conception of health. Furthermore, as influence conditions, the questions concerning personal and previous work experiences were highlighted. Therefore, a lack of knowledge of these professionals in the face of public policies was verified, in especial what concerned SUS, demanding not only urgent changes in their academic education but also in their political implication in the face of social questions and users.
\end{abstract}

Keywords: Psychologist performance. Integrality. Primary helth care. Public policies.

Resumen: La interdisciplinaridad es una de las principales estrategias empleadas por el Sistema Único de Salud (SUS) para el ofrecimiento de servicios en el sector público, especialmente los que involucran los cuidados primarios; en ese cuadro, se encuentra la Psicología. Este estudio busca verificar qué principios sirven de norte a la práctica de los psicólogos de João Pessoa, PB en los servicios de Atención Básica a la Salud. Participaron 17 psicólogos, la mayoría del sexo femenino, con edad que variaba entre 23 y 58 años $(M=44 ; D P=11,8)$. De los principios norteadores a la práctica de esos profesionales, levantados por medio de un cuestionario socio-laboral, emergieron tres categorías temáticas: 1) los principios y directrices del SUS, 2) los valores personales y 3) la concepción de salud. Además, como condiciones influenciadoras, obtuvieron destaque las cuestiones referentes a las experiencias personales y profesionales anteriores. Delante de eso, se puede verificar una deficiencia en el conocimiento de los psicólogos frente a las políticas públicas, en especial, en lo que atañe al SUS, lo que demanda no sólo urgentes transformaciones en su formación académica sino también en su envolvimiento político frente a las cuestiones sociales y a los usuarios.

Palabras clave: Actuación del psicólogo. Integralidad. Atención primaria de salud. Políticas públicas.

O campo da saúde, na vertente da saúde coletiva, passa a abrir, com mais veemência, suas portas à Psicologia, acreditando que essa ciência, além das contribuições na área da saúde mental, também assume um papel significativo na compreensão do processo do adoecimento. A inserção do psicólogo em instituições de saúde, especificamente nas que envolvem os cuidados primários, como por exemplo, as unidades básicas de saúde (UBS) e a Estratégia Saúde da Família (ESF), constitui uma realidade cada vez mais presente. A inclusão desse profissional em tais serviços, concomitantemente à de outras categorias profissionais, vem responder à nova visão estabelecida sobre o processo saúdedoença, que já não se refere à saúde apenas como ausência de doença, mas como fruto da relação entre um conjunto de fenômenos físicos, psíquicos e socioeconômicos a que estão submetidos os indivíduos (Rutsatz \& Câmara, 2006).

Essa nova concepção de saúde tem sido palco, nos últimos anos, de muitas discussões que envolvem não só a própria reflexão 
dos profissionais sobre suas práticas mas também o levantamento de propostas de transformações no que concernem as políticas públicas em saúde e os modelos tecnoassistenciais vigentes (Paim \& Almeida Filho, 1998). Levando em conta tais questões, de numerosos encontros realizados desde fins da década de 70, tanto de cunho internacional quanto nacional, ressalta-se a Conferência Internacional sobre os Cuidados Primários em Saúde, realizada em 1978, em Alma-Ata, Cazaquistão, e a I Conferência Internacional sobre Promoção de Saúde, realizada em 86, em Ottawa, Canadá. Já no Brasil, cabe destacar a realização da $8^{a}$ Conferência Nacional de Saúde, em 1986, que, embasada nos movimentos sociais da época, especialmente, no movimento da reforma sanitária, deu origem a um sistema público de saúde que se propõe atender a toda a população. Esse sistema, de caráter democrático, que, anos depois, se transformou no atual Sistema Único de Saúde (SUS), fundamentava-se nos princípios da universalidade, igualdade e integralidade dos serviços, garantindo, através de seu reconhecimento na Constituição Federal de 1988, a saúde como dever do Estado e direito de todos os cidadãos (Feuerwerker, 2005).

A preocupação do SUS com relação aos aspectos primários, para Bodstein (2002), remete a um dos maiores desafios ligados à sua consolidação, que é a estruturação de um novo modelo tecnoassistencial em saúde com vistas a substituir o modelo individual-assistencialista que ainda persiste na maioria das práticas de saúde. Esse modelo hegemônico, criado nos moldes do positivismo e na objetividade da ciência, prioriza a formação profissional voltada somente para o enfoque curativo, e é desenvolvido principalmente com base na visão hospitalocêntrica, medicamentalizante (Cecílio, 1997, p. 471), que tem a figura do médico como centro. Por essa razão, as práticas em saúde ainda constituem, muitas vezes, intervenções verticalizadas, e assumem uma organização hierárquica que não permite nem um diálogo com outros saberes nem muito menos a criação de espaços de intersubjetividades, onde os usuários teriam o papel central, como propõe Ayres (2001).

Nesse sentido, por objetivar mudanças nessa relação entre equipe de saúde - usuários de maneira a estabelecer uma relação dialógica e participativa com a comunidade, a necessidade de incorporar outros saberes nesses serviços se mostra, a cada dia, uma ferramenta imprescindível para se alcançar tal finalidade. A inserção desses saberes por meio de uma compreensão interdisciplinar, conforme Peduzzi (2001), tomaria a saúde em um contexto mais amplo, envolvendo, portanto, tanto elementos de cunho individual e familiar como de cunho social. Com base nessas questões, vários momentos de discussão e reflexão estão sendo promovidos pelos conselhos e por profissionais de várias categorias, no intuito de lutar com mais afinco e maiores embasamentos pela sua inserção definitiva nos serviços de saúde pública, o que inclui, principalmente, os serviços de atenção primária, mais especificamente, os que envolvem a Estratégia Saúde da Família.

Desse modo, com vistas a atender essas solicitações, o Ministério da Saúde, através da portaria no 154 , de 24 de janeiro de 2008, criou o Núcleo de Apoio à Saúde da Família (NASF). Esses núcleos, que contam com a presença de vários profissionais de diferentes áreas de conhecimento (como assistentes sociais, fonoaudiólogos, nutricionistas, educadores físicos, farmacêuticos, terapeutas ocupacionais e psicólogos, entre outros) têm por objetivo ampliar a abrangência e o foco das ações da Atenção Básica, de maneira a garantir a plena integralidade no cuidado dos usuários que compõem o SUS (Brasil, 2008). De caráter contra-hegemônico, a forma de atuação dessas equipes parte das reflexões e críticas feitas pelos estudiosos 
da saúde coletiva à forma verticalizada e alienante com que se estruturam os serviços em saúde (Campos, 1999), tendo por base o matriciamento. Os apoiadores matriciais, como são conhecidos, têm por função, a partir da visão de clínica ampliada, promover uma relação dialógica entre profissionais e usuários e criar possibilidades de ações que garantam a integralidade do atendimento (Conselho Regional de Psicologia-SP [CRPSP], 2009). Apesar de algumas unidades básicas de saúde já contarem com a presença de alguns psicólogos em seus serviços, é nesse quadro de matriciamento e trabalho interdisciplinar que a Psicologia tem sido convocada, atualmente, a participar.

No entanto, mesmo com a possibilidade de estruturação de um fazer interdisciplinar e horizontal nas práticas em saúde, a inserção de novos profissionais no contexto da saúde pública ainda é um assunto que merece muita discussão no cotidiano do trabalho, isso porque muitas profissões ainda apresentam uma formação deficitária no que concerne aos problemas sociais, principalmente àqueles que envolvem a formulação e a implementação de políticas públicas. No caso da Psicologia, em particular, em virtude de a sua formação se voltar, ainda, para o molde clínico-individualista, inúmeras discussões foram e estão sendo realizadas, e grandes são os questionamentos acerca da responsabilidade social do psicólogo, dos seus saberes e de sua adequação à realidade do SUS (Bock, 2003; Dimenstein, 2001).

Mas é preciso considerar que a contribuição do saber psicológico para o processo saúdedoença não se deu da noite para o dia, nem muito menos em um vazio social. Sua inserção e práticas nesse contexto obedeceram a uma série de eventos, entre eles à adequação aos diferentes modelos tecnoassistenciais em saúde que vigoraram no Brasil e, especialmente, à necessidade das classes elitistas de manter o poder e o controle social (Bock, 2003). Desse modo, para que se possa entender os passos que a Psicologia percorreu até sua inserção no campo da saúde coletiva, é necessário fazer um breve percurso histórico de suas práticas no âmbito da saúde pública, de maneira que se possa perceber que essa abertura veio atender, inicialmente, uma ideologia que se preocupava de longe com as questões sociais.

\section{A Psicologia e as políticas públicas de saúde no Brasil}

Apesar do reconhecimento da profissão, no Brasil, só ter ocorrido na década de 60 , atividades ligadas à prática psicológica no campo da saúde pública já eram datadas dos anos 30 no País. Como afirmou Bock, as atividades psicológicas no Brasil sempre foram marcadas pelo compromisso com a ideologia dominante, a da elite, contribuindo, assim, muito pouco para que transformações sociais ocorressem no País. Inicialmente, suas ações estavam voltadas para a aplicação de técnicas psicométricas e psicodiagnósticas, objetivando o controle e a normatização dos sujeitos, especialmente no contexto da saúde mental, campo de ação ao qual a Psicologia ainda é bastante associada (Pereira \& Pereira Neto, 2003; Spink \& Matta, 2007). Com o advento da Medicina sanitarista, nos anos 40 e 50, e com sua ideologia ligada à necessidade de educar a população sobre sua responsabilidade na aquisição de certas enfermidades, a prática psi se estende à saúde das classes populares, especialmente, no que concerne à saúde do trabalhador e à saúde materno-infantil (Spink \& Matta, 2007).

Somente a partir dos anos 60, com a regulamentação da profissão, a popularização da psicanálise por todo o Brasil (Dimenstein, 2000; Pereira \& Pereira Neto, 2003) e a introdução e a hegemonização do modelo assistencial-privatista, é que a Psicologia adentra pela arena da saúde pública com mais afinco. Nesse período, segundo Garcia 
(2006), típico do modelo tecnoassistencialcurativista que se consolidava, priorizavase o enfoque biomédico, e as ações em Psicologia apresentavam ainda mais um caráter individualizado e especializado, procurando direcionar a aplicação de técnicas psicoterapêuticas, típicas do consultório, para um contexto mais amplo, como o contexto hospitalar. Nessa conjuntura, as práticas psicológicas apenas fortaleceram a visão biomédica e o modelo hospitalocêntrico, com a crescente aceitação, por parte do psicólogo, desse novo campo de trabalho.

Por fim, ao final dos anos 70 e meados dos anos 80, frente à pressão dos vários movimentos sociais ocorridos, entre eles o movimento da reforma sanitária, a Psicologia é, mais uma vez, chamada a responder às demandas da saúde pública. No entanto, na atual conjuntura, a inserção dos psicólogos no SUS pretende obedecer a uma nova ótica, muito diferente das teorias e práticas a que estava acostumada. Segundo Menengon e Coêlho (2007), o psicólogo, no SUS, tem por objetivo, pelo menos no plano do ideal, não só romper a dicotomia entre a saúde física e a saúde mental, mas, acima de tudo, buscar um diálogo com outros saberes, obedecendo, assim, ao princípio da integralidade do atendimento com vistas a se pensar e a se construir propostas de atuação eficazes voltadas para as verdadeiras necessidades sociais. Esse novo olhar exige, assim, que o profissional de Psicologia assuma novas posturas tanto em relação à sua ideia de sujeito, visto agora como um ente ativo e participativo, como à ideia de sociedade, em que a noção de coletivo deve permear suas práticas.

Mas, apesar de a arena da saúde se abrir à ciência psicológica, o que tem se observado (Boarini, 2007; Camargo-Borges \& Cardoso, 2005; Dimenstein, 1998; Velasques, 2003) é que esta ainda tem apresentado um arcabouço teórico e prático insuficiente e inadequado ao exercício demandado por esse novo fazer em saúde. Um dos primeiros estudos sobre a inserção do psicólogo no contexto da saúde coletiva, em especial, nas unidades básicas de saúde, realizado por Jackson e Cavallari (1991, citados por Spink, Bernardes, Santos, \& Gamba, 2007), já apontava a necessidade de novas práticas e de mudanças na sua formação.

A explicação para essa atuação discrepante, segundo os autores anteriormente citados, está, principalmente, atrelada à própria formação em Psicologia que, tradicionalmente, sempre se voltou para questões de cunho individualista, procurando responder a teorias de caráter terapêuticocurativo-assistencialista. Não é à-toa que, ainda segundo esses autores, a prática clínica constitua sua maior referência, sendo um fator ainda muito estimulado pela maioria dos cursos de graduação em Psicologia no País. Outro fator relacionado é, segundo Dimenstein (1998), a crença dos profissionais na clientela idealizada, típica de consultórios, proveniente da classe elitista, que está longe de assemelhar-se à classe popular, principal usuária do SUS. Para a autora, esse fator resulta, muitas vezes, em certo mal-estar (p.73) para os profissionais, que passam a questionar a necessidade e a importância de seu trabalho nesses serviços.

Diante dessas deficiências, o atual quadro da inserção do psicólogo, não só nas políticas de saúde mas também nas demais políticas públicas, tem preocupado os pesquisadores da área e os próprios profissionais da categoria, que, pressionados por esse novo enfoque em saúde, lutam por mudanças na formação que atendam essas demandas. $\mathrm{Na}$ tentativa de averiguar como acontecem essas práticas e de desenvolver instrumentos de orientação a esse novo fazer psi, o Conselho Federal de Psicologia (CFP) criou, em agosto de 2006, o Centro de Referência Técnica em Psicologia e Políticas Públicas (CREPOP), com 
o intuito de, a partir de pesquisas realizadas sobre a atuação desses profissionais no contexto das políticas públicas, desenvolver instrumentos metodológicos que pudessem servir de possíveis guias para o exercício da sua profissão.

Entretanto, sem a existência desses instrumentos norteadores, o que se tem, atualmente, no campo da saúde é uma gama de profissionais de Psicologia que trabalham de forma inadequada e descontextualizada do que pregam os princípios e diretrizes do SUS, e, muitas vezes, com o total desconhecimento deste. Nesse sentido, ressalta-se a relevância social que esse fenômeno apresenta nos dias de hoje, convocando cada vez mais o olhar dos pesquisadores para a busca por melhores formas de enfrentamento desse processo. Assim, para tentar compreender como a Psicologia tem abraçado esse novo contexto, este estudo teve por objetivo verificar quais princípios estão servindo de norte às atuais práticas psicológicas no contexto da Atenção Básica.

\section{Método}

O presente estudo, de natureza descritiva e exploratória, foi realizado com psicólogos que atuam em serviços de atenção primária à saúde no Município de João Pessoa, PB no período de setembro de 2008 a março de 2009. No contexto da saúde, a capital paraibana está demarcada territorialmente sob a forma de cinco Distritos Sanitários (DS) que recortam toda a extensão territorial da cidade. Estes têm por objetivo organizar a rede de cuidado e garantir à população pessoense acesso aos serviços básicos (atenção primária), aos especializados (média complexidade) e à assistência hospitalar (alta complexidade). Para o presente estudo, escolheu-se como campo da pesquisa, dentre as instituições responsáveis pelos serviços primários, aquelas que continham pelo menos um profissional de Psicologia em seu quadro de funcionários.
No momento da coleta de dados, as instituições que contavam com psicólogos eram: três unidades de Saúde da Família, três unidades básicas de saúde e quatro Distritos Sanitários (estes últimos, envolvendo os psicólogos que fazem parte das equipes que compõem o NASF). Participaram da pesquisa 17 do total de 20 profissionais de Psicologia que atuam nos serviços de atenção primária no Município. A idade desses profissionais variou entre 23 e 59 anos ( $M=44$ anos; $D P=11,8)$, sendo a maioria do sexo feminino $(\mathrm{N}=15)$. O tempo de trabalho na saúde pública foi acima de 10 anos $(\mathrm{N}=12)$, predominando a formação clínica $(\mathrm{N}=12)$.

O instrumento utilizado na coleta de dados foi um questionário sociolaboral cujas questões versavam, principalmente, sobre os aspectos norteadores da prática desses profissionais no contexto da Atenção Básica. A aplicação do instrumento foi realizada de forma individual, no local de trabalho dos participantes, no período em que não estavam exercendo suas atividades e em locais mais reservados, com o objetivo de não prejudicar a coleta de dados. Devido ao número reduzido de participantes, que não permitia a utilização de estatísticas mais avançadas, os dados foram analisados somente através de estatística descritiva, na qual se utilizaram medidas de posição (média), de variabilidade (desvio-padrão) e distribuição de frequências.A pesquisa foi conduzida dentro de padrões éticos exigidos pela Comissão Nacional de Ética em Pesquisa/ Conselho Nacional de Saúde/Ministério da Saúde (CONEP/CNS/MS), conforme disposto na Resolução CONEP no 196/96. Este estudo foi aprovado pelo Comitê de Ética em Pesquisa do Centro de Ciências da Saúde da Universidade Federal da Paraíba - CEP/CCS.

\section{Resultados e discussão}

Dos 17 psicólogos participantes, seis trabalham em UBS, três em unidades da ESF e oito exercem a função de apoiadores matriciais, 
fazem parte das equipes do NASF e estão dispostos em quatro dos cinco Distritos Sanitários. As diferenças com relação à função exercida por esses profissionais receberam atenção neste estudo, pois revelaram que essa variável, mais do que apontar possíveis diferenças quanto à atuação dos psicólogos no contexto da Atenção Básica, traz também acentuadas diferenças quanto ao conhecimento que esses profissionais possuem com relação aos princípios e diretrizes do SUS. Desse modo, para melhor compreensão dos resultados, este estudo direcionou sua análise de dados à comparação descritiva desses dois grupos.

$\mathrm{Na}$ tentativa de compreender as bases que sustentam as práticas desses profissionais, foram indagados dos participantes quais os principais motivos que os levaram a atuar no contexto da ABS. Tanto os psicólogos das UBS/ESF (05) quanto os apoiadores matriciais (04) apontaram, em sua maioria, o interesse pessoal como principal fator motivador para o trabalho nesse contexto. No entanto, quatro (04) psicólogos das UBS/ESF e três (03) apoiadores matriciais viram o trabalho na Atenção Básica como uma oportunidade de se inserir no mercado de trabalho. Desse modo, assim como os dados obtidos por Spink et al. (2007), vários são os fatores que levam os psicólogos a atuarem no SUS, mas os que parecem fazer tal escolha são aqueles relacionados à identificação e à carreira e inserção laboral.

Em seguida, quando questionados sobre quais princípios servem de guia à sua atuação nesse contexto, as respostas emitidas se conjugaram em três categorias temáticas, a saber: 1) princípios e diretrizes do SUS, 2) valores pessoais e 3) concepção de saúde. A Tabela 1 apresenta esses resultados.

Tabela 1. Princípios orientadores da prática dos participantes nos serviços de Atenção Básica

\begin{tabular}{|c|c|c|c|c|c|c|}
\hline \multirow{4}{*}{$\begin{array}{l}\text { Princípios orientadores da prática } \\
\text { (categorias) }\end{array}$} & \multicolumn{4}{|c|}{ Citações } & \multirow{3}{*}{\multicolumn{2}{|c|}{ TOTAL }} \\
\hline & \multirow{2}{*}{\multicolumn{2}{|c|}{$\begin{array}{c}\text { Psicólogos das } \\
\text { UBS/ESF }\end{array}$}} & \multirow{2}{*}{\multicolumn{2}{|c|}{$\begin{array}{c}\text { Apoiadores } \\
\text { matriciais }\end{array}$}} & & \\
\hline & & & & & & \\
\hline & $\mathrm{F}$ & $\%$ & $\mathrm{~F}$ & $\%$ & $\mathrm{~F}$ & $\%$ \\
\hline \multicolumn{7}{|l|}{ Princípios e diretrizes do SUS } \\
\hline $\begin{array}{l}\text { (Ex: universalidade, integralidade, } \\
\text { democracia, participação popular, etc.) }\end{array}$ & 07 & 40 & 16 & 67 & 23 & 55 \\
\hline \multicolumn{7}{|l|}{ Valores pessoais } \\
\hline \multicolumn{6}{|l|}{ (Ex: solidariedade, respeito ao } & 28 \\
\hline \multicolumn{7}{|l|}{ Concepção de saúde } \\
\hline $\begin{array}{l}\text { (Ex: equilíbrio, bem-estar, promoção } \\
\text { e prevenção em saúde, etc.) }\end{array}$ & 05 & 27 & 02 & 08 & 07 & 17 \\
\hline TOTAL & 18 & 100 & 24 & 100 & 42 & 100 \\
\hline
\end{tabular}

* Respostas múltiplas admitidas ** Respostas idiossincráticas $(f=2 ; \%=5)$

Como apresentado na Tabela 1, a primeira categoria emergente em ambos os grupos referiu-se aos princípios e diretrizes do SUS, sendo que, para o grupo dos apoiadores matriciais, essa categoria 
se apresentou muito mais significativa. $\mathrm{O}$ dado levanta possíveis considerações sobre o conhecimento que esses dois grupos de profissionais possuem com relação ao SUS e aos seus princípios e diretrizes.

No tocante aos apoiadores matriciais, não foi nenhuma surpresa tal constatação, uma vez que estes relataram, em momento anterior, possuir formação complementar à graduação, especialmente, em cursos que compreendiam discussões sobre políticas de saúde e o SUS $(\mathrm{N}=07)$, formação que possivelmente permitiu maior empoderamento de tais conceitos por parte desses profissionais e direcionou suas práticas para a realização de intervenções com base nas referidas propostas. Já no caso dos psicólogos das UBS/ ESF, infere-se que, apesar de a maioria não apresentar nenhuma formação acadêmica com relação ao SUS $(\mathrm{N}=06)$, o contato no dia a dia do seu trabalho com as discussões e reflexões acerca da temática pode ter acarretado certo grau de conhecimento desses aspectos pelo grupo. Nesse sentido, a consciência sobre a importância dos princípios citados para as atuais intervenções em saúde estaria, no caso desses profissionais, em particular, relacionada mais à sua prática do que a discussões científicas.

Justificativas como essas se fundamentam nos ideais de transformação organizacional do sistema de saúde propostos por movimentos como o da saúde coletiva. Pensando em soluções rápidas para o problema da má formação profissional para a atuação no SUS, o Ministério da Saúde lançou, recentemente, a Política Nacional da Educação Permanente em Saúde (PNEPS), cujo objetivo é produzir uma reflexão e uma análise crítica sobre os processos de formação e de trabalho a que estão submetidos esses indivíduos, de maneira a promover transformações e melhores qualificações nas práticas em saúde (Brasil, 2009). Nesse sentido, cursos de capacitação e formação estão sendo ministrados nos diferentes serviços de saúde com o intuito de abranger o maior número possível de profissionais da área. Toda essa discussão gera, portanto, maior conhecimento dos profissionais sobre os princípios e diretrizes do SUS, mesmo que de forma superficial.

A segunda categoria emergente se referiu aos valores pessoais. Esta se apresentou muito mais significativa para os psicólogos das UBS/ ESF do que para os apoiadores matriciais. Tal diferença, no entanto, também não surpreende, uma vez que, sem o domínio dos conceitos e com uma formação deficiente no que tange ao SUS, é justificável que os psicólogos das UBS/ESF baseiem sua atuação em aspectos pessoais e socialmente aceitáveis. Essa afirmativa pode ser considerada a partir do que já foi discutido em outros estudos (Yamamoto \& Castro, 1998; Yamamoto, Siqueira, \& Oliveira, 1997), que profissões como a Psicologia, representada em sua maioria por mulheres, são permeadas de crenças que direcionam os sujeitos a agirem em função do outro, para o outro. Assim, aspectos valorativos como solidariedade, respeito, ética e compromisso social podem ser facilmente justificados nos discursos desses profissionais como fatores condicionantes à sua prática. Esse pensamento explica, também, o aparecimento desses elementos no discurso dos apoiadores matriciais.

Por fim, a última categoria emergente foi relativa à concepção de saúde. Assim, como a categoria valores pessoais, essa também foi mais significativa para os psicólogos das UBS/ ESF que para os apoiadores matriciais. Apesar do entendimento e da importância atribuída a conceitos como prevenção e promoção de 
saúde, aspectos essenciais para se perceber a saúde como fenômeno multideterminado (Gioia-Martins \& Rocha, 2001; Kubo \& Botomé, 2001), a visão da saúde ligada à noção de bem-estar e de equilíbrio do corpo parece ainda fazer parte do pensamento desses profissionais. A razão para tal fato pode ser atribuída à definição, amplamente difundida, da OMS, que concebe a saúde como um estado de completo bem-estar, físico, psicológico e social (OMS, 1946). Com base em tal definição, compreende-se dever empregar, nas intervenções em saúde, a noção de facilitadora e/ou provedora do equilíbrio entre esses fatores.

Essa concepção de saúde como estática e dicotômica à doença, no entanto, vem sendo desconstruída nos últimos anos, especialmente quando se leva em consideração a complexidade que envolve o fenômeno do adoecimento. A utilização de conceitos como, por exemplo, promoção de saúde e qualidade de vida vem resgatar não só a importância de se intervir na multiplicidade de elementos que influenciam o estar doente (e não somente a cura do corpo) mas também de ressaltar os próprios indivíduos como sujeitos ativos nesse processo. Nesse sentido, a forma como as pessoas percebem os aspectos de sua vida e agem diante das adversidades, envoltas na definição da qualidade de vida (Fleck, 2007), merece ocupar posição de destaque quando se pretende construir intervenções efetivas em saúde.

A introdução desses novos conceitos, para Buss (2000), faz com que as práticas em saúde abarquem medidas preventivas não só sobre o corpo mas também sobre o ambiente físico e sobre os estilos de vida coletivos, reforçando tanto os direitos quanto a responsabilidade dos sujeitos pela sua própria saúde. Desse modo, a percepção da saúde como elemento multideterminado, segundo Kubo e Botomé (2001), aumenta as possibilidades de mudança no comportamento dos profissionais que atuam na área, tanto em relação ao tipo de intervenção a ser feita quanto em relação ao tipo de conhecimento a ser produzido sobre o fenômeno. No caso da Psicologia, por exemplo, sua reflexão e atuação não se limitariam às intervenções em saúde mental, mas envolveriam todas as relações possíveis entre essa variável psicológica e as demais que envolvem o processo saúde-doença. No caso particular deste estudo, no entanto, pode-se inferir que esses profissionais ainda se utilizam de práticas ligadas ao pensamento individual-curativista, referente ao modelo biomédico, entrelaçadas aos ideais de promoção de saúde pregados pelo SUS e ao seu novo modelo de atenção em saúde.

Entretanto, entende-se que, tão importante quanto a formação para o trabalho dos profissionais de saúde, está a crença que possuem em sua capacidade profissional. De acordo com Bandura (1989, citado por Pereira \& Almeida, 2004), mesmo tendo todos os requisitos formadores e práticos necessários ao exercício profissional em determinado contexto, o indivíduo precisa se sentir capaz de conseguir realizá-lo. Desse modo, conhecer a percepção que os psicólogos possuem com relação à sua capacidade profissional pode ser um fator crucial na tentativa de se compreender como esses mecanismos internos poderiam estar influenciando o seu comportamento, no sentido de motivá-los ou de acomodá-los em sua prática no contexto da ABS.

Assim sendo, os participantes também foram questionados, com base em três afirmativas, sobre qual a percepção que possuem quanto a sua capacidade profissional para atuar no 
contexto da ABS. Com relação ao grupo dos psicólogos das UBS/ESF, quatro afirmaram que sempre tiveram capacidade profissional para atuar nesse contexto, dois afirmaram que somente hoje têm capacidade profissional para fazê-lo e três afirmaram que ainda lhes faltam algumas capacidades profissionais, mas que conseguem reverter a situação. No caso do grupo dos apoiadores matriciais, cinco deles afirmaram que hoje têm capacidade profissional para atuar no contexto da ABS, e três afirmaram que ainda lhes faltam algumas capacidades profissionais, mas que também conseguem reverter a situação.

A análise do item traz algumas considerações importantes. Sabe-se que a atuação do psicólogo no contexto da Atenção Básica leva em consideração vários fatores. A presença cada vez mais numerosa de psicólogos nesse contexto, incentivados pelo teóricos da saúde coletiva, por exemplo, pode levar o indivíduo a pensar que, mesmo com uma formação deficitária, sua categoria apresenta condições profissionais suficientes para atuar no âmbito do SUS. Desse modo, a identificação com seu grupo profissional pode levá-lo a perceber de maneira positiva sua capacidade pessoal. Outro exemplo que pode ser citado refere-se às situações que envolvem o reconhecimento do seu trabalho, feito não só pelos colegas de trabalho mas também, e principalmente, pelos usuários. Por sentir-se útil e por ter seu trabalho reconhecido, a percepção do psicólogo com relação à sua capacidade profissional pode apresentar alto grau de pontuação. No presente caso, a análise desse item reforça os dados dos itens anteriores, uma vez que demonstra, no caso do grupo dos psicólogos da UBS/ESF, a crença na sua formação acadêmica como suficiente para atuar nos serviços de ABS.

Ainda com o objetivo de conhecer melhor as bases que servem de norte para o trabalho dos psicólogos nos serviços primários, pediuse aos participantes que, de um conjunto de dez proposições, marcassem, por ordem de prioridade, somente aquelas referentes às condições que atribuíam à sua forma de atuação. As que obtiveram maior destaque e maior grau de importância para ambos os grupos de profissionais foram as questões referentes às trocas de experiências com os colegas de trabalho e/ou profissão $(f=16)$, às experiências de trabalho anteriores $(f=15)$, às relações estabelecidas com os usuários $(f=15)$ e às avaliações e reflexões feitas sobre a prática do seu trabalho $(f=14)$. Nesse caso, não houve diferença significativa entre os grupos, demonstrando assim, que, de uma forma em geral, os psicólogos que trabalham nos serviços de Atenção Básica à Saúde em João Pessoa, PB atribuem como fundamentais, para o desenvolvimento de suas atuais práticas, o conhecimento e as experiências acumuladas em seu percurso profissional, somados às avaliações que fazem dessas práticas. A análise desse item aponta um dos principais problemas relacionados à inserção do psicólogo no contexto da saúde: a falta de instrumentos e de direcionamentos técnico-metodológicos ao seu exercício. Nesse sentido, por mais que se tenha conquistado esse tão disputado espaço de atuação, nada mais justificável que esses profissionais se apoiem no seu cotidiano e na suas experiências com colegas de trabalho/ profissão para construírem e apreenderem esse novo fazer psi.

\section{Considerações finais}

O fazer interdisciplinar constitui uma das principais ferramentas utilizadas pelo SUS como forma de garantir a integralidade no atendimento aos seus usuários, com vistas a construir um novo modelo de atenção em saúde. Essa forma de trabalho tem sido 
considerada fundamental, principalmente nas ações que envolvem os cuidados primários em saúde, cujo fortalecimento, segundo Azevedo (2007), envolve a ampliação do acesso aos usuários e a qualificação e a reorientação das práticas embasadas na promoção da saúde. Entretanto, verificase, no dia a dia de trabalho das equipes de saúde, que a realização de um atendimento verdadeiramente integral e condizente com o que pregam os princípios e diretrizes do SUS ainda está longe de alcançar resultados satisfatórios. Uma das razões para tal fato emerge das próprias atividades desenvolvidas pelos profissionais que ainda priorizam atuações e conhecimentos técnicos de caráter individual, além de um conhecimento precário do SUS e das suas propostas de intervenção, o que dificulta a integração entre os diversos saberes presentes nas equipes de saúde.

A atuação do psicólogo, nesse contexto, portanto, não é diferente. Como pôde ser observado nesta pesquisa, para os grupos de psicólogos estudados, especificamente, o grupo de psicólogos que atua nas UBS/ ESF, a atuação nos serviços de Atenção Básica à Saúde ainda apresenta uma série de limitações. Estas remetem, inicialmente, à sua formação acadêmica, que, realizada nos moldes da clínica tradicional, acabou por afastá-los das discussões que envolvem os problemas sociais e as políticas públicas, aqui, especificamente, a política do SUS. Em consequência, destaca-se a própria consciência desses profissionais, que não enxergam suas deficiências e, portanto, não buscam alternativas para suprir essas carências. O resultado é que ainda atuam conforme aquilo que aprenderam na Academia, fundamentados pelo modelo biomédico hegemônico, alheios, portanto, e, por que não dizer, incapazes de agir de modo crítico e inovador frente aos problemas de saúde que trazem os princípios e diretrizes do SUS. Levando-se em consideração tais questões, torna-se difícil pensar e/ou observar práticas integrativas ou interdisciplinares nesse grupo de profissionais, uma vez que suas ações ainda se apresentam despreparadas e descontextualizadas da noção de coletivo que, atualmente, guiam as práticas em saúde.

Ademais, mesmo tendo o grupo dos psicólogos que compõem o NASF apresentado um conhecimento maior do SUS e de seus princípios e diretrizes do que os psicólogos das UBS/ESF, a falta de instrumentos teóricometodológicos como guia para a sua atuação nesse contexto, de uma forma geral, também se apresenta como um obstáculo à sua prática, cujo know-how, construído principalmente com base em suas experiências pessoais e profissionais anteriores, ainda carrega o ideário individualista e psicologizante presentes em sua formação. Desse modo, a conflitante relação entre o fazer psicológico tradicional, arraigado às práticas clínicas tradicionais e a esse novo fazer em Psicologia, interdisciplinar e com uma visão de sujeito coletivo que emerge das políticas sociais, pode vir a ocasionar uma crise na identidade desses profissionais.

Cabe, então, refletir sobre a quem se deve responsabilizar por essa relação conflituosa. Será somente a má formação acadêmica que insiste em seguir a passos curtos a urgente transformação que se faz necessária a uma nova práxis psicológica no campo da saúde pública ou aos próprios profissionais que enraizaram seu pensamento em um modelo de atuação que está aquém da realidade social? Levando-se em consideração os resultados aqui encontrados sem, no entanto excluir a influência de outros elementos nesse processo, como, por exemplo, a 
própria organização do sistema de saúde e as questões político-ideológicas vigentes, acredita-se que a responsabilidade seja compartilhada. É imprescindível que as instituições formadoras reconheçam suas deficiências e reestruturem seus cursos de graduação para atender as demandas desse novo campo de atuação, de maneira que, como citou Souza (2006), as "vivências embaraçosas frente às inexperiências para esse trabalho" (p. 178) sejam vistas não como um retrocesso, mas como um grande passo em busca da inserção definitiva. Mas é também fundamental que os próprios profissionais de Psicologia reconheçam a necessidade de mudança e se percebam como elementos influenciadores, cujas ações repercutem no dia a dia do seu trabalho e na vida dos usuários. Diante disso, não se pode deixar de ressaltar a importância do envolvimento político do psicólogo com as questões sociais e com os usuários. Para que o psicólogo tenha suas práticas condizentes com o que prega o SUS, acredita-se que não precise ter apenas a formação necessária sobre esse sistema ou atuar conforme seus princípios norteadores, mas deve ter, acima de tudo, a consciência de que é um instrumento, um dispositivo de transformação. Atuar nos serviços primários à saúde implica, assim, não só ter conhecimento, capacidade técnica e espaço aberto à atuação, mas, principalmente, o desejo de lutar e agir em busca de verdadeiras transformações sociais. 
Francisca Marina de Souza Freire

Mestra em Psicologia social pela Universidade Federal da Paraíba, Paraíba - PB - Brasil.

Ana Alayde Werba Saldanha Pichelli

Doutora em Psicologia social pela Universidade Federal da Paraíba, Paraíba - PB - Brasil.

E-mail: analayde@terra.com.br

*Endereço para envio de correspondência:

Rua Rosa Lima dos Santos, 64, Ed. Grumari, ap. 305 Jardim Cidade Universitária - João Pessoa, Paraíba - PB Brasil CEP 58051-590.

E-mail: marinasfreire@hotmail.com

Recebido 9/9/2009, 1a Reformulação 19/4/201, Aprovado 27/4/2010. 
Referências
Ayres, J. R. M. (2001). Sujeito, intersubjetividade e práticas de saúde. Ciência \& Saúde Coletiva, 6(1), 63-72.

Azevedo, A. L. M. de. (2007). Acesso à atenção à saúde no SUS: o PSF como (estreita) porta de entrada. Dissertação de Mestrado em Saúde Pública, Centro de Pesquisas Aggeu Magalhães, Fundação Oswaldo Cruz, Recife, PE.

Bock, A. M. B. (2003). Psicologia e sua ideologia: 40 anos de compromisso com as elites. In A. M. B. Bock (Org.), Psicologia e o compromisso social (pp. 15-28). São Paulo: Cortez

Boarini, M. L. (2007). A formação do psicólogo. Psicologia em Estudo, 12(2), 443-444.

Bodstein, R. (2002). Atenção Básica na agenda da saúde. Ciência e Saúde Coletiva, 7(3), 401-412.

Brasil. Ministério da Saúde. (2008). Portaria no 154, de 24 de janeiro de 2008. Recuperado em 05 de abril de 2008, de http://www.saude.ba.gov.br/dab/arquivos/portaria154.2008. pdf

Brasil. Ministério da Saúde. (2009). Política Nacional de Educação Permanente (PNEPS). Recuperado em 20 de junho de 2009, dehttp://189.28.128.100/portal/saude/profissional/area. cfm?id_area $=1265$

Buss, P. M. (2000). Promoção de saúde e qualidade de vida. Ciência e Saúde Coletiva, 5(1), 163-177.

Camargo-Borges, C., \& Cardoso, C. L. (2005). A psicologia e a estratégia saúde da família: compondo saberes e fazeres. Psicologia \& Sociedade, 17(2), 26-32.

Campos, G. W. S. (1999). Equipes de referência e apoio especializado matricial: um ensaio sobre a reorganização do trabalho em saúde. Ciência \& Saúde Coletiva, 4(2), 393-303.

Cecílio, L. C. de O. (1997). Modelos tecnoassistenciais em saúde: da pirâmide ao círculo, uma possibilidade a ser explorada. Cadernos de Saúde Pública, 13(3), 469-478.

Conselho Regional de Psicologia-SP. (2009). NASF, um novo apoio para a atenção básica. Jornal de Psicologia, (158). Recuperado em 20 de abril de 2009, de http://www.crpsp. org.br/crp/midia/jornal_crp/158/frames/fr_conversando_ psicologo.aspx

Dimenstein, M. D. B. (1998). O psicólogo nas unidades básicas de saúde: desafios para a formação e atuação profissionais. Estudos de Psicologia, 3(1), 53-81.

Dimenstein, M. D. B. (2000). A cultura profissional do psicólogo e o ideário individualista: implicações para a prática no campo da assistência pública à saúde. Estudos de Psicologia, 5(1), 95-121.

Dimenstein, M. D. B. (2001). O psicólogo e o compromisso social no contexto da saúde coletiva. Psicologia em Estudo, 6(2), 57-63.

Feuerwerker, L. (2005). Modelos tecnoassistenciais, gestão e organização dos trabalhos em saúde: nada é indiferente no processo de luta para a consolidação do SUS. Interface Comunicação, Saúde, Educação, 9(18), 489-506.

Fleck, M. P. de A. (Org.) (2007). A avaliação de qualidade de vida: guia para profissionais da saúde. Porto Alegre: Artmed.

Garcia, A. S. (2006). A inserção do psicólogo no SUS: reflexões sobre a prática. In Anais do XIX Encontro de Psicologia de Assis (pp. 35-41). Assis, SP: Universidade Estadual Paulista.

Gioia-Martins, D., \& Rocha Jr., A. (2001). Psicologia da saúde e o novo paradigma: novo paradigma? Psicologia, Teoria e Prática, 3(1), 35-42.

Kubo, O. M., \& Botomé, S. P. (2001) Formação e atuação do psicólogo para o tratamento em saúde e em organizações de atendimento à saúde. InterAÇÃO, 5, 93-122.

Menegon, V. S. M., \& Coêlho, A. E. L. (2007). Psicologia e sua inserção no sistema público de saúde: um painel longitudinal de temas-foco publicados em periódicos brasileiros. In M. J. Spink (Org.), A psicologia em diálogo com o SUS: prática profissional e produção acadêmica (pp. 175-205). São Paulo: Casa do Psicólogo.

Organização Mundial da Saúde. (1946). Constituição. Nova York: Author.

Paim, J. S., \& Almeida Filho, N. (1998). Saúde coletiva: uma "nova saúde pública" ou campo aberto a novos paradigmas? Revista de Saúde Pública, 32(4), 299-316.

Pereira, M. G., \& Almeida, P. (2004). Auto-eficácia na diabetes: conceito e validação de escala. Revista Eletrônica Análise Psicológica, 3(22), 585-595.

Pereira, F. M., \& Pereira Neto, A. (2003). O psicólogo no Brasil: notas sobre seu processo de profissionalização. Psicologia em Estudo, 8(2), 19-27.

Peduzzi, M. (2001). Equipe multiprofissional de saúde: conceito e tipologia. Revista de Saúde Pública, 35(1), 103-109.

Rutsatz, S. N. B., \& Câmara, S. G. (2006). O psicólogo na saúde pública: trajetórias e percepções na conquista desse espaço. Aletheia, 23, 55-64.

Souza, V. D. (2006). O psicólogo e a saúde pública: uma leitura fenomenológica das vivências cotidianas de estagiários na Atenção Básica. Tese de Doutorado, Pontifícia Universidade Católica de Campinas, Campinas, SP.

Spink, M. J. P., Bernardes, J. S., Santos, L., \& Gamba, E. A. C. (2007). A inserção do psicólogo em serviços de saúde vinculados aos SUS: subsídios para entender os dilemas da prática e os desafios da formação profissional. In M. J. Spink (Org.), A psicologia em diálogo com o SUS: prática profissional e produção acadêmica (pp. 53-79). São Paulo: Casa do Psicólogo.

Spink, M. J., \& Matta, G. C. (2007). A prática profissional psi na saúde pública: configurações históricas e desafios contemporâneos. In M. J. Spink (Org.), A psicologia em diálogo com o SUS: prática profissional e produção acadêmica (pp. 25-48) São Paulo: Casa do Psicólogo.

Velasques, M. B. (2003). Intervenções de psicólogos em unidades básicas de saúde do grande $A B C$. Dissertação de Mestrado, Programa de Pós-graduação em Psicologia da Saúde, Universidade Metodista de São Paulo, São Bernardo do Campo, SP.

Yamamoto, O. H., \& Castro, A. H. F. (1998). A psicologia como profissão feminina: apontamentos para estudo. Estudos de Psicologia, 3(1), 147-158.

Yamamoto, O. H., Siqueira, G. da, \& Oliveira, S. C. C. (1997). A psicologia no Rio Grande do Norte: caracterização geral da formação acadêmica e do exercício profissional. Estudos de Psicologia, 2(1), 42-67. 